\title{
Thymic Stromal Lymphopoietin in Cutaneous Immune-Mediated Diseases
}

\begin{abstract}
Si-Hang Wang and Ya-Gang Zuo*
Department of Dermatology, National Clinical Research Center for Dermatologic and Immunologic Diseases, Translational Medicine Center, Peking Union Medical College Hospital, Chinese Academy of Medical Sciences and Peking Union Medical College, Beijing, China
\end{abstract}

Thymic stromal lymphopoietin (TSLP) was initially demonstrated to be critical in regulating inflammatory responses among various allergic disorders (such as atopic dermatitis, food allergy, and asthma). Although two isoforms (short form and long form) of TSLP have been demonstrated in human tissues, the long form of TSLP (IFTSLP) is strongly implicated in the pathogenesis of allergies and cutaneous immune-mediated diseases. The immunomodulatory activity of IfTSLP varies widely, driving T helper (Th) cells polarizing Th2 and Th17 immune responses and inducing itch. Moreover, IfTSLP is closely associated with skin fibrosis, epidermal hyperplasia, angiogenesis, and homeostatic tolerogenic regulations. This review highlights significant progress from experimental and clinical studies on ITSLP in cutaneous immune-mediated diseases (atopic dermatitis, psoriasis, bullous pemphigoid, systemic sclerosis, chronic spontaneous urticaria, Behçet's disease, vitiligo, rosacea, systemic lupus erythematosus, and alopecia areata). We also offer original insights into the pleiotropic properties of the cytokine TSLP in various pathophysiological conditions, with significant clinical implications of TSLP-targeted therapies for immune-mediated skin diseases in the future.

Keywords: thymic stromal lymphopoietin, inflammation, allergy, autoimmunity, skin diseases

\section{INTRODUCTION}

Thymic stromal lymphopoietin (TSLP), a distant paralog of interleukin (IL)-7, is a pleiotropic molecule within the IL-2 family $(1,2)$. Murine TSLP was initially detected in a conditioned medium from the supernatant of a thymic stromal cell line, sustaining the growth of B cells and modulating thymocytes proliferation in vitro $(3,4)$. When added to long-term bone marrow or fetal liver cultures, TSLP stimulated the B220+/IgM+ B cells expressing k light chains on their surfaces (4). Two isoforms for TSLP [long-form TSLP (lfTSLP) and short-form TSLP (sfTSLP)] were first determined by Harada et al. in human bronchial epithelial cells (5). The functional and high-affinity receptor of lfTSLP isoform includes both the TSLP receptor (TSLPR) subunit (binding to TSLP with low affinity) and the IL-7 receptor $\alpha$-chain $(6,7)$. Human homology of TSLP was initially identified by in silico methods in $2001(8,9)$. The human TSLP gene is mapped to chromosome 5q22.1, near the atopic molecular cytokine cluster $(8,9)$. Its protein has two isoforms consisting of 159 amino acids in length, and the other, 63 amino acids $(5,9)$. Murine TSLP is a 140 -amino acid protein located on murine chromosome $18(1,5,8,9)$. Human and murine TSLP/TSLPR signaling pathways share similar functional characteristics despite relatively low genetic homology, indicating the 
TSLP/TSLPR axis is conserved among humans and mice $(10,11)$. During the initiation of inflammation, the principal sources of TSLP are keratinocytes, epithelial cells, fibroblasts, mast cells, macrophages, and dendritic cells (DCs) $(10,12,13)$. The functional TSLPR is expressed by DCs, innate lymphoid cells (ILCs), mast cells, B cells, T cells, eosinophils, monocytes, and several non-hematopoietic cell populations such as epithelial cells $(10,12-17)$.

Over the past two decades, experimental and clinical studies have demonstrated TSLP to be a potent initiator of type 2 allergic inflammatory responses in humans and mice (11). Furthermore, multiple reviews have described the role of TSLP in allergic disorders [atopic dermatitis (AD), airway allergy, and foodhypersensitivity reaction], autoimmune diseases, infections, and cancers $(10,11)$. Moreover, TSLP has also been linked to intestinal protection and homeostatic tolerogenic regulations (18). Epithelial cell-intrinsic TSLP has a significant impact upon tolerogenic DCs generation that promotes the regulatory $\mathrm{T}$ cell differentiation in the intestine and thymus (19-21). This review will focus on emerging messages on lfTSLP-related allergic disorders and immune-mediated skin diseases, adding new insights into the pleiotropic properties of lfTSLP in various pathophysiological conditions.

\section{A DICHOTOMY BETWEEN TWO ISOFORMS OF TSLP}

Emerging data have provided more substantial evidence of a dichotomy between the variants of TSLP in humans: IfTSLP and sfTSLP (5). SfTSLP is short of the N-terminal sequence of lfTSLP but shares the identical domain at the C-terminal (5). This group further revealed that the TSLP promoter polymorphisms of the two SNPs Rs2289276 and Rs2289278 increase transcription factor activating protein-1 binding and subsequent lfTSLP production. In that way, the promoter SNPs correlate with the susceptibility of asthma in children and adults (22).

The mRNA derived from an internal promoter in intron 2 of TSLP has been predicted to encode the sfTSLP, consisting of 63 amino acids (5). Interestingly, the mRNA was constitutively expressed in keratinocytes, epithelial cells, and lung fibroblasts (5). This expression remains unchanged even after challenging with lipopolysaccharide capable of inducing lfTSLP transcription $(5,23-26)$. However, the expression of sfTSLP at the protein level and its physiological role remain unknown. Human sfTSLP mRNA is the predominant isoform of TSLP in keratinocytes and salivary glands (26). Several studies demonstrated sfTSLP is not regulated similarly to lfTSLP and may exert antibacterial and anti-inflammatory effects (26-30). Although these experiments have suggested sfTSLP is implicated in homeostatic conditions and inflammations, further investigations are needed to determine whether it is expressed as a functional protein in vivo and the mechanism of regulation in the signaling pathways involved in sfTSLP (for example, the contribution of vitamin D3 and nuclear receptor peroxisome proliferator activated receptor- $\gamma)(25,27)$. Next, this review will exclusively describe lfTSLP and its participation in allergies and cutaneous immunities

\section{TSLP IN ALLERGY}

TSLP's roles in type 2 allergic responses have been extensively studied (Figure 1). Type 2 immunity, characterized by the abundance of $\mathrm{CD} 4+\mathrm{T}$ helper 2 (Th2) cells, eosinophils, mast cells, basophils, and group 2 ILCs, prevents the host from extracellular parasitic insult but causes chronic allergy (31). During the initiation of Th2 responses, epithelial exposure to stimuli such as proteolytic allergens, bacteria, parasites, and chemicals triggers a variety of protease activating receptors and pattern recognition receptors on barrier epithelial cells, inducing the production of TSLP, IL-25, and IL-33. Furthermore, the generation of endogenous danger-associated molecular patterns can amplify the release of pro-Th2 cytokines by epithelial cells (31). DCs triggered by TSLP induce naive T cells to differentiate into Th2 cells through co-stimulatory molecules CD86 and OX40L (32). This DC activation may further enhance Th2 allergic inflammation via macrophage-derived and thymus and activation-regulated chemokine production (12). Subsequently, these cytokines/chemokines result in the production of Th2 molecules IL-4, IL-5, IL-13, and tumor necrosis factor (TNF)- $\alpha$ by CD4+T cells and reduction of IL-10 and IFN- $\gamma(11,12,32)$. Additional research showed that TSLP induced the rapid Th2 cell maturation via the TSLPR expressed on naïve CD4+T cells, indicating a possible earlier activation of $\mathrm{T}$ cells triggered by $\operatorname{TSLP}(33,34)$. Moreover, TSLP can modulate the proliferation of Th2 cell linage through high-level TSLPR on rodent effector T cells (35). It has also been implicated in innate immunity, promoting the release of type 2 cytokines from mast cells (14) and priming type 2 ILCs to express IL-5 and IL-13 in an IL-25 and IL-33-independent manner (36). Additionally, TSLP may contribute to the amplification of macrophage polarization (37).

TSLP's role in activating basophils has been intensively studied in the past decade, and the role of TSLP in triggering basophils in Th2 differentiation remains highly controversial $(16,38,39)$. Basophils can initiate and enlarge inflammation by secreting IL-4 and are linked with Th2 immune responses (40). A previous study using a vitamin D3 analog MC903 (calcipotriol) -induced mouse model revealed that DCs activated by TSLP prime naïve T cells to secret IL-3 via OX40L, and IL-3 could recruit basophils resulting in Th2 priming (41). The cascade characterized by orchestrated "DC-T-basophil-T" through the OX40L-IL-3 axis precedes the production of IL- 4 by T cells so that basophils could provide an earlier source of IL-4 to prime type 2 immune responses (41). Other studies further demonstrated that the "TSLP-basophil-IL-4" signaling is crucial in Th2 polarization $(42,43)$. TSLP and basophils are closely associated with the development of intestinal food allergy in response to epicutaneous sensitization with food antigen $(44,45)$. Critically, TSLP-induced basophil is related to the evolution of allergy from the skin to the remote gastrointestinal mucous membrane via IL-4 (42). This sequence was delineated as the "atopic march" characterized by a sequential disease progression from $\mathrm{AD}$ to food allergy and asthma $(42,46)$.

Nevertheless, Whether TSLP directly activates basophils remains disputed (39). Several studies have illustrated heterogeneity within basophil cell lineages (TSLP-elicited and 


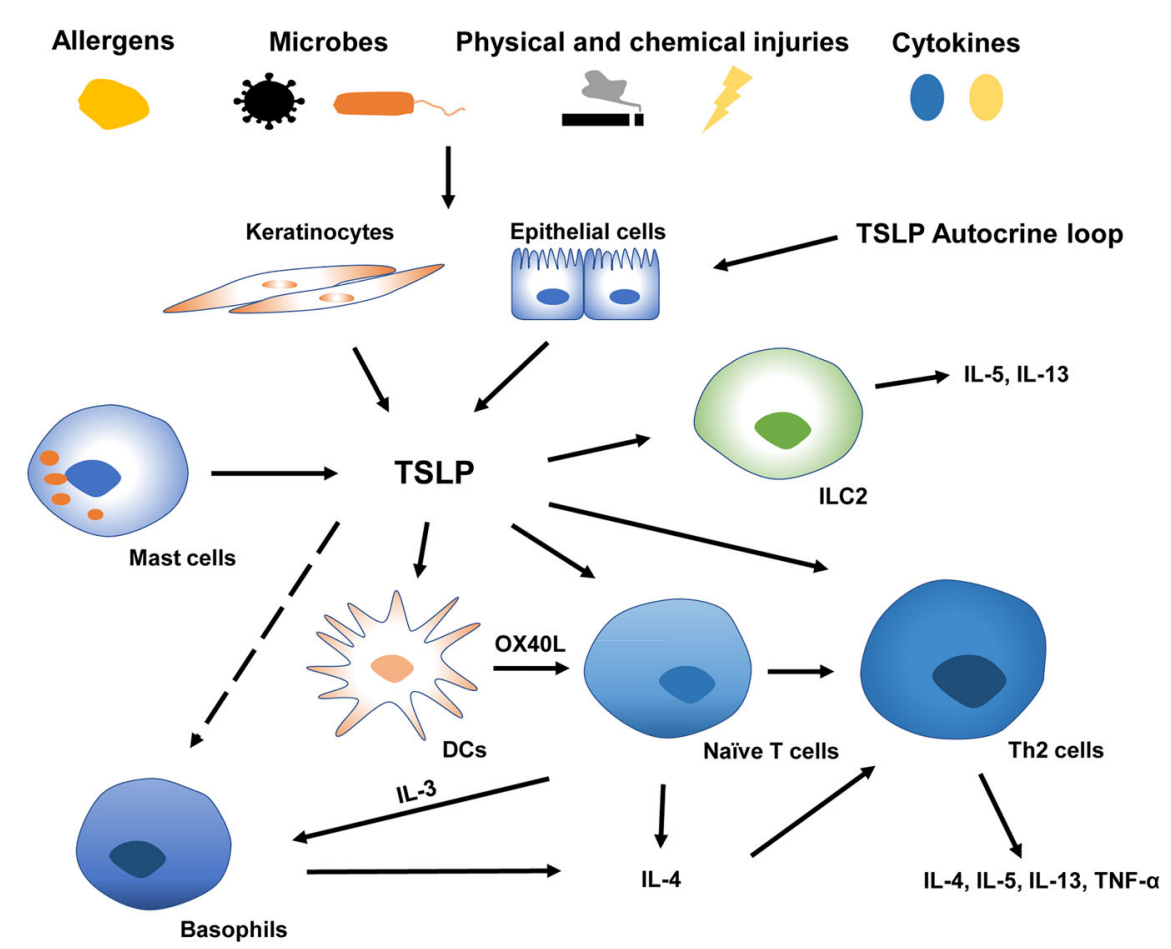

FIGURE 1 | TSLP in type 2 allergic inflammatory responses at barrier surfaces. A variety of endogenous or environmental factors may contribute to the production and release of TSLP from barrier surfaces. Keratinocytes and epithelial cells derived TSLP activates DCs, ILC2, naïve CD4+T cells, and Th2 cells (Whether TSLP directly affects basophils remains controversial). TSLP-triggered DC induces naive T cells to release IL-3 via OX4OL, which is capable of recruiting basophils polarizing Th2 inflammation. TSLP, thymic stromal lymphopoietin; IL, interleukin; Th2 cells, type 2 T helper cells; OX40L, OX40 ligand; DCs, Dendritic cells; ILC2, type2 innate lymphoid cells.

IL-3-elicited basophils). They claimed that TSLP affected bonemarrow cells to enhance basophil hematopoiesis independently of IL-3, suggesting that basophil activation was driven at least in part by $\operatorname{TSLP}(16,38)$. Several clinical experiments showed the upregulation of TSLPR in patients with allergic rhinitis and asthma after allergen stimulation. However, TSLPR expression on basophils is minimally associated with asthma severity, indicating a limited role for basophils in TSLP-induced inflammation $(17,38,47)$. Based on these findings, basophils are involved in the polarization, expansion, and progression of Th2 polarization and appear to be critical in the pathogenesis of $\mathrm{AD}$, allergic asthma and rhinitis, and eosinophilic chronic rhinosinusitis (48). However, the mechanism of the activation of basophils by TSLP under these abnormal conditions warrants additional investigations. Moreover, tactics targeting the "basophil-IL-4" pathway may prevent the evolution of type 2 allergic responses from the skin to internal organs.

The functions of cytokines/chemokines in the Th2 immune network overlap considerably. The complex interactions in the molecular network may be related to the patients' age, heredity, environment, and disease location. Ultimately the cytokine milieu at the barrier surfaces collectively contributes to the clinical observed symptoms and signs in various pathophysiological courses. Next, we will exclusively elaborate on the effects of TSLP in numerous immune-mediated skin conditions.

\section{TSLP AND CUTANEOUS IMMUNE-MEDIATED DISORDERS}

TSLP has been shown to be a robust driver of Th2 responses at barrier surfaces. Accordingly, the involvements of TSLP in AD, a canonical type 2 cutaneous disorder, have been intensively studied. Besides, numerous investigations in both human and mouse skin implicated TSLP in a great variety of cutaneous disorders beyond $\mathrm{AD}$. The following sections will describe the immune-mediated skin diseases linked with TSLP and the mechanisms of action through which TSLP produces its effect.

\section{AD}

$\mathrm{AD}$, a relapsing inflammatory skin condition, is also called atopic eczema and features intense pruritus with a family history of atopies $(49,50)$. TSLP is closely linked with AD pathogenesis (Figure 2). Soumelis et al. first reported the involvement of TSLP in the immunopathogenesis of atopic diseases in 2002 (12). Through immunohistochemical analysis, the overexpression of TSLP in the keratinocytes of both acute and chronic lesions was identified in $\mathrm{AD}$ patients, while its expression was absent from non-diseased or non-lesional skin (12). TSLP expression in stratum corneum was more remarkable in $\mathrm{AD}$ patients than in controls. Furthermore, it was correlated with Scoring Atopic Dermatitis Index, especially with the stratum corneum hydration 


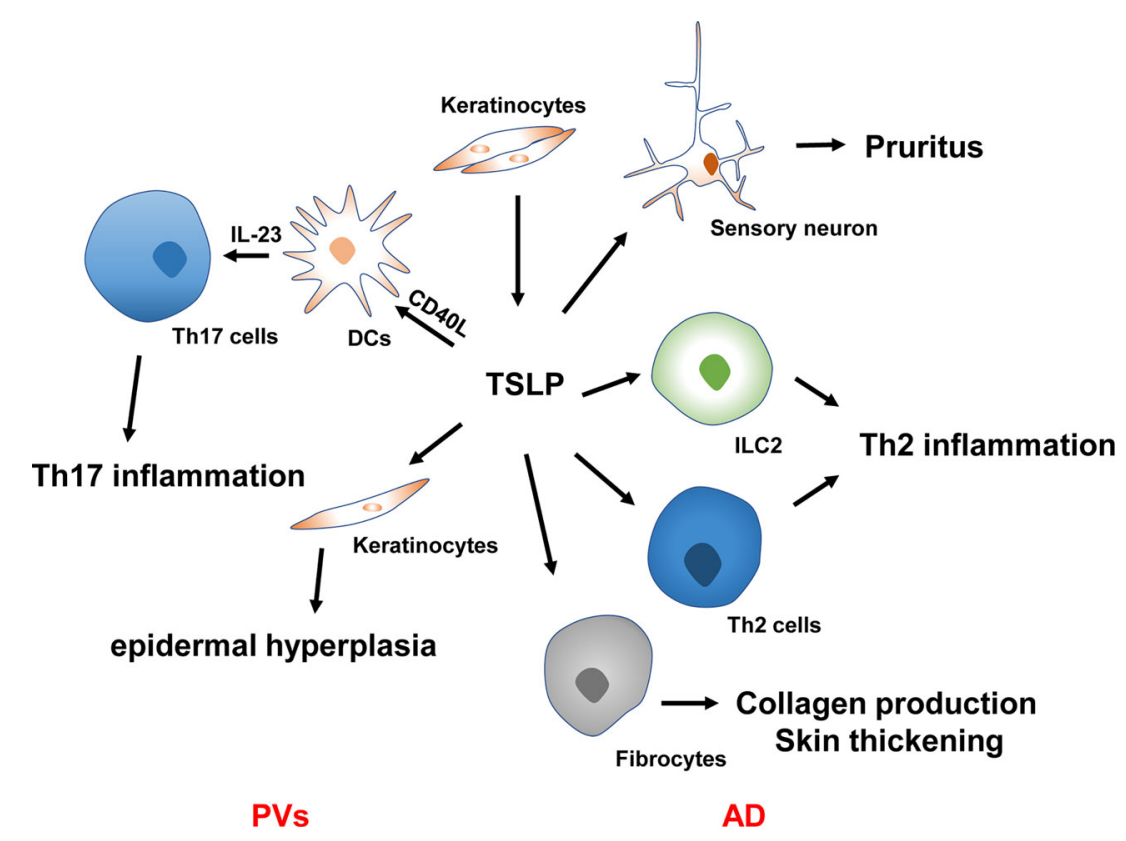

FIGURE 2 | TSLP in the pathogenesis of AD and PVs. TSLP causes Th2 inflammation, pruritus, collagen production, and skin thickening in the pathogenesis of AD. TSLP synergy with CD4OL to promote DC activation and IL-23 production, resulting in Th17 inflammation in the context of PVs. TSLP also regulates keratinocyte proliferation in the plaque of PVs, leading to epidermal hyperplasia. PVs, psoriasis vulgaris; AD, atopic dermatitis; ILC2, type 2 innate lymphoid cells; Th2 cells, type 2 Thelper cells; Th17 cells, type 17 T helper cells; IL, interleukin.

and dry skin score, indicating its overexpression corresponds to the epidermal barrier function (51). More importantly, keratinocytes-targeted TSLP overexpression induced AD-like lesions with an evident alteration in the infiltrate of Th2-related cells and an increased sera level of IgE (52). The persistence of AD is also related to the TSLP variation. Multiple studies have shown that specific gene polymorphism is closely associated with the genetic susceptibility of $\mathrm{AD}$. A cohort study following more than 800 American children showed that the TSLPrs 1898671 homozygosity contributed to the less-persistent $\mathrm{AD}$ in White children (53). More recently, another large-scale longitudinal cohort study found that the IL-7R variant rs11567725 can regulate the function of TSLP variants, suggestive of TSLP to be a potential genetic risk evaluation index of AD (54). These findings revealed that the epidermal production of TSLP is correlated with the clinically observed lesions, severity, and persistence of AD. TSLP-triggered DCs prime naïve T cells skewing Th2 immunity (12). Subsequent sensitization results in the occurrence of AD's eczematous lesions.

Pruritus is considered a hallmark of $\mathrm{AD}$ and impairs a patient's quality of life (QOL), leading to persistent scratching in $\mathrm{AD}$ patients (55). Physical damage attributed to chronic scratching significantly increased cutaneous TSLP levels (56). More importantly, TSLP may indirectly cause itching by inducing Th2-related cytokines that activate sensory neurons (57-59). TSLP was also demonstrated to function as a pruritogen. It acts directly on dorsal root ganglia neurons expressing TSLPR to trigger itch signals via the transient receptor potential cation channel A1 (60). A very recent research showed TSLP could induce the periostin secretion in keratinocytes that causes itching through the periostin receptor expressed on a subset of sensory neurons, indicating that TSLP may be involved earlier in AD development by inducing itching, scratching, and skin barrier dysfunction (61). Moreover, monoclonal antibodies targeting these cytokines have favorable functions in alleviating pruritus in $\mathrm{AD}$ patients $(62,63)$.

$\mathrm{AD}$ treatment has traditionally been confined to topical immunosuppressant use (50). Systemic immunosuppressants and phototherapy are applied in severe $\mathrm{AD}$ patients (50). Crisaborole ointment, a topical phosphodiesterase 4 inhibitor, and Dupilumab, a monoclonal antibody inhibiting IL-13 and IL4 functions, have recently been approved by the US FDA for AD treatment $(50,64)$. Early-phase clinical trials targeting the immune pathway underlying the axis of TSLP-OX40L-OX40 have been tested in AD patients. A humanized antibody GBR830 targeting OX40, a costimulatory molecule expressed mainly on $\mathrm{T}$ cell subtypes, led to significantly lower clinical severity scores and decreased cutaneous AD gene signatures (Th1 signaling-IFN- $\gamma$ and CXCL10, Th2 signaling-IL-31, CCL11, and CCL17, Th17/ Th22 signaling-IL-23p19, IL-8, and S100A12) versus placebo (65). A small phase 2 a clinical trial using class III topical corticosteroids plus tezepelumab, a TSLP monoclonal antibody that blocks the interaction of TSLP to its receptor complex, achieved a numerical but statistically non-significant reduction in eczema-severity scores over placebo at week 12, with more excellent week 16 responses (66). The clinical trials on TSLP suggest agents inhibiting TSLP and TSLP-related molecules may be helpful in $\mathrm{AD}$ patients. 


\section{Psoriasis}

Psoriasis vulgaris (PVs) is a chronic immune-related skin disorder substantially detrimental to patients' QOL (67). Additionally, recent evidence demonstrated PVs as a systemic entity related to cardiovascular, endocrine, metabolic, gastrointestinal, renal, and consequentially psychological conditions such as depression and anxiety (68). Skin DC activation and IL-23 mediated induction of Th17 signaling is the primary pathophysiology of PVs $(68,69)$. TSLP's role in PVs was initially elucidated in 2014 by Volpe and collaborators (70). Using immunohistochemistry, they revealed TSLP was significantly elevated in the untreated PVs patients' epidermis (70). An in vitro study proved that TSLP and T cellderived CD40L synergy contribute to DC maturation and subsequent IL-23 production by skin DCs and primary blood obtained from patients with PVs, which can be inhibited by a specific type 2 immune cytokine IL-4 in a dose-dependent manner (70). Several experiments further demonstrated that TSLP expression was more vigorous in skin lesions than in unaffected skin of PVs patients (71). Serum TSLP is also statistically increased and correlated with the severity of this disorder, suggesting its role as a prospective disease activity biomarker in psoriasis patients $(71,72)$. Although the experiments noted above propose that TSLP production is increased and plays a vital role in PVs development, another study showed minimal expression of TSLP in psoriatic lesions through immunohistochemical staining (73). The discrepancies may be attributed to the previous application of steroids suppressing TSLP production, thus pointing to the induction and function of TSLP are associated with PVs' pathophysiology but not with therapeutical measures.

In addition to skin inflammation, PVs' hallmarks include excessive keratinocyte proliferation, impaired differentiation, and epidermal hyperplasia in psoriatic plaque (68). Although various studies have highlighted the effects of TSLP in the skin DCs activation, its performances in the interaction of epidermal cells have rarely been investigated $(11,29)$. Recent studies have demonstrated TSLP, as an autocrine and paracrine factor, produced mainly by mutant bulge hair follicle stem cells and basal keratinocytes, can stimulate adjacent non-mutant epidermal cells to hyper-proliferate and express vascular endothelial growth factor $\alpha$, thus contributing to skin inflammation and epidermal hyperplasia in PVs patients (74). Local injection of TSLP antibodies in the psoriasis-like mouse model led to skin inflammation regression, reduced epidermal hyperplasia, decreased vascular endothelial growth factor $\alpha$ expression, and epidermal inhibition of STAT-5 phosphorylation (74).

Psoriatic arthritis (PsA), a musculoskeletal inflammation associated with cutaneous manifestations, is a common comorbidity in PVs patients and develops in up to $40 \%$ of this disorder $(68,75)$. Angiogenesis occurs in the early stage of PsA, promoting the recruitment of leukocytes and ultimately destroying neighboring tissues $(76,77)$. In vitro studies using primary synovial fibroblasts (SFC) derived from PsA patients showed that TSLP was significantly elevated in PsA SFC-conditioned medium (76). Furthermore, fibroblasts from PsA synovium could induce the formation of endothelial cell tubes and increase angiogenic function through upregulation of TSLP, consistent with the results observed from cervical cancer previously $(76,78$, 79). These data may support the blockade of SFC-derived TSLP as an optional method to alleviating abnormal angiogenesis in patients with PsA. Overall, these results extend the role of TSLP in regulating Th17 immune responses, keratinocyte proliferation, and angiogenic function in different microenvironments, with implications for other autoimmune conditions such as rheumatoid arthritis. More importantly, inhibition of the TSLP/ TSLPR pathway could be beneficial for psoriasis patients and warrants additional clinical investigations.

\section{Bullous Pemphigoid}

Bullous pemphigoid (BP), a highly prevalent type of skin autoimmune subepidermal blistering disease that mainly affects the elderly, typically manifests as pruritic vesicles and bullae (80). The pathophysiology of BP is still unclear, but autoantibodies to structured proteins in the dermal-epidermal junction and Th2 immunity are likely involved in this disorder $(81,82)$. Multiple studies have identified a markedly increased concentration of TSLP in skin lesions, blister fluid, and sera of patients with BP, especially in the lower layer of the epidermis (83-86). Furthermore, the levels of TSLP in serum correlated with those in blisters (86). These findings imply that TSLP is involved in the immunopathogenesis of BP and could be released by keratinocytes in the epidermis of BP.

Mice models have played a vital role in elucidating the mechanisms of BP (83). One study using a BP-like mouse model with the deletion of the NC16A domain of BP180 (termed $\triangle \mathrm{NC16 \textrm {A }}$ mice) showed spontaneous skin inflammation accompanied by elevated skin TSLP level and itching. This study

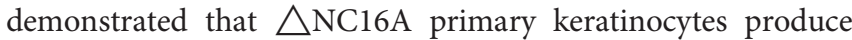
significantly more TSLP when stimulated with TNF- $\alpha$ in vitro. More importantly, increased expression of TSLP can also be

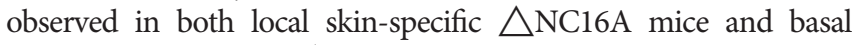
keratinocyte-specific $\triangle \mathrm{NC16A}$ mice, suggesting that BP180 dysfunction may induce basal keratinocytes to produce TSLP. Nevertheless, how BP180 dysfunction in keratinocytes triggers the release of TSLP and the molecular pathways/interactions in this process require further clarification.

Persistent pruritus is the most bothersome symptom in BP patients and significantly affects patient's QOL (80). Given the critical role of TSLP in inducing itching in pruritic skin disorders, TSLP may also be involved in BP itching $(83,87)$. In the skin of $\triangle \mathrm{NC16A}$ mice, significantly increased TSLP expression correlates with the severity of itching, while IgE or histamine is not involved in the mechanism underlying severe itching (83). Moreover, blockade of TSLP activity reduced scratching in $\triangle$ NC16A mice (83). However, the enhanced TSLP expression did not correlate with the severity of itching in BP patients (85). Thus, the pathogenic contribution of TSLP may be limited in BPrelated itching.

The downstream mechanisms of TSLP in BP have received little attention. Li et al. showed that the number of DC-specific intercellular adhesion molecule-3-grabbing non-integrin (DCSIGN)-positive DCs in BP lesional skin was higher than that in healthy controls and correlated with more robust TSLP 
expression in the epidermis and blisters of BP patients (86). In comparison, Langerhans cells (LCs) in the epidermis of $\mathrm{BP}$ lesional skin were less likely to be associated with increased TSLP expression (86). Moreover, DC-SIGN-positive DCs, but not LCs, expressing langerin, were positive for TSLPR (86). These data suggest that keratinocytes-derived TSLP may directly activate DCs. However, no studies thus far have verified the downstream mechanisms of the interactions between TSLP and DCs in BP patients.

\section{Systemic Sclerosis}

Systemic sclerosis (SSc), characterized by fibrosis of the skin and internal organs and vasculopathy, is an autoimmune disorder with high morbidity and mortality (88). It is generally believed vascular dysfunction, autoimmunity (especially the involvement of Th2 and Th17 responses), and fibrosis are the three essential characteristics of SSc (88-90). TSLP is also vital in the proinflammatory and profibrotic profiles of SSc (Figure 3). Multiple types of research have demonstrated expression of TSLP is significantly elevated in the skin of SSc-like mice models and patients (91-95). However, the contributors to the production of TSLP in these conditions remain controversial. Usategui et al. showed that TSLP overexpression was primarily linked to keratinocytes (92). In contrast, Christmann et al. failed to identify the difference between SSc and healthy donors (91). They demonstrated specific noticeable perivascular staining attributed to CD163+ macrophages and a few CD4+ and CD8+ T cells (91). The conflicting results may be ascribed to the specific study sources, and the disease phases since the infiltration of immune cells is commonly observed in the early stage of SSc (96). Furthermore, Truchetet et al. showed that TSLP expression is elevated in the epidermis and dermis of SSc patients. Interestingly, increased dermal numbers of TSLP-producing endothelial cells were strongly correlated with skin fibrosis (93). Also, serum TSLP was increased in SSc patients and associated with vascular dysfunction, indicating a possible earlier involvement of TSLP since vasculopathy occurs early in the progression of SSc (93).

Currently, the mechanisms underlying the triggers driving the expression of TSLP in SSc remain unknown. Toll-like receptors (TLR), IL-13, interferons, and TNF superfamily member LIGHT, have been demonstrated to induce TSLP release in SSc $(96,97)$. TLR activation, particularly TLR-3 triggering, induced TSLP expression by fibroblasts in vitro (92) and poly(I-C), a TLR-3 ligand, was confirmed to induce TSLP expression in infiltrating immune cells in a SSc murine model (91). Moreover, plateletintrinsic IL-1 $\beta$ can contribute to skin fibrosis via the induction of TSLP production by human dermal microvascular ECs in a dosedependent manner (93). LIGHT can directly induce TSLP in keratinocytes and synergize with transforming growth factor (TGF)- $\beta$ to further affect TSLP expression (97). The specific potential of TSLP inducing TLR activation in SSc patients remains unknown. By exposing fibroblasts to plasma from SSc, Usategui et al. failed to detect enhanced TSLP expression (92). Further investigations are needed to clarify the precise mechanisms involved in the overexpression of TSLP in SSc.

The downstream effects of TSLP in SSc have not yet been fully elucidated. In the early phases of SSc, overexpression of TSLP was crucial for inducing profibrotic processes and

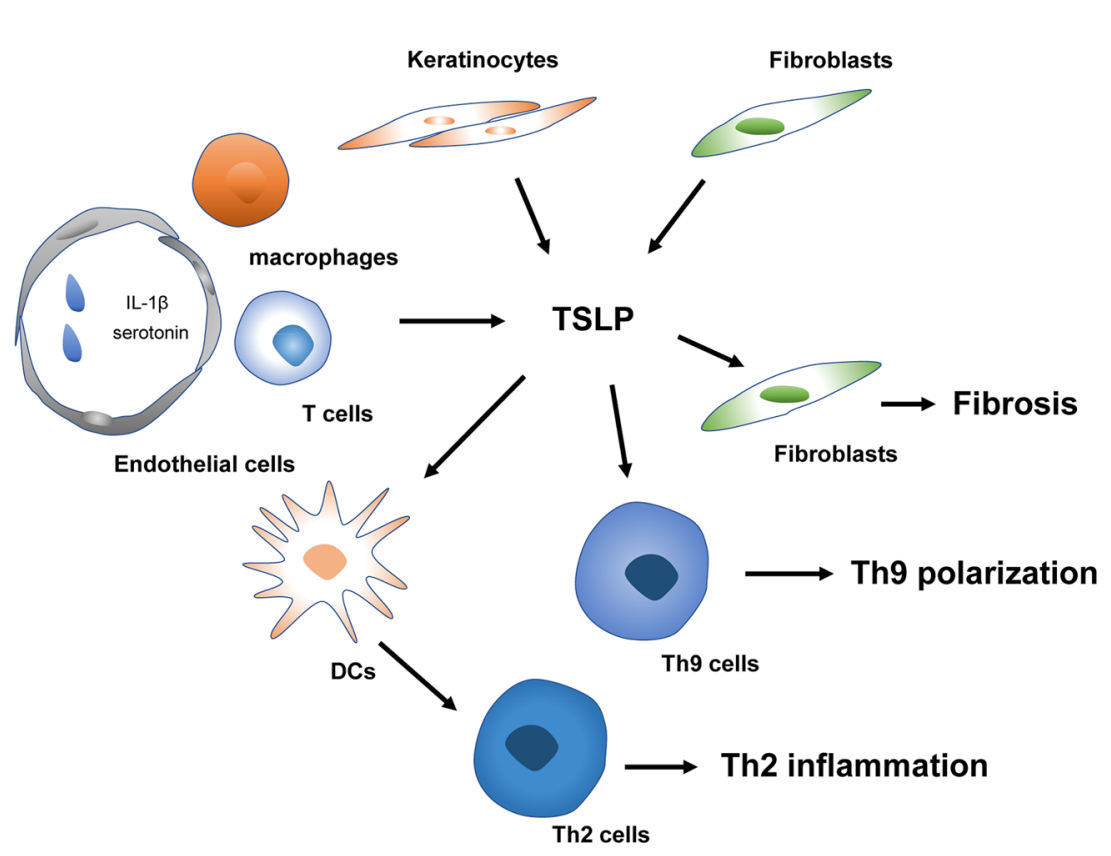

FIGURE 3 | TSLP in the pathogenesis of SSc. TSLP mediates early Th2 and Th9 inflammation and late fibrosis of SSc. Platelets derived IL-1 $\beta$ and serotonin trigger TSLP released by vascular endothelial cells. TSLP contributes to Th2 and Th9 polarization in the early stage of SSc. Keratinocytes and fibroblasts releasing TSLP can modulate the fibrosis process in combination with TGF- $\beta$ in the late phase of SSc. SSc, systemic sclerosis; IL, interleukin; Th2 cells, type 2 T helper cells; Th9 cells, type 9 T helper cells; DCs, Dendritic cells; TGF- $\beta$, transforming growth factor- $\beta$. 
proinflammatory molecules IL-13 and IL-17 (92). Furthermore, TSLP injection in the mouse skin induced clusters of genes assessed by microarray that IL-13 and TGF- $\beta$ similarly enhance [e.g., plasminogen activator inhibitor 1 (PAI-1), thrombospondin 1 , bone morphogenetic protein 1 , and secreted phosphoprotein 1 (SPP-1)] (91). Moreover, TSLP deficiency inhibited TGF- $\beta$ induced cutaneous fibrosis and abrogated several genes induced by TGF- $\beta$, involving PAI-1 and SPP-1 (91). In vivo and in vitro studies further demonstrated that TSLP strongly promoted Smad2 phosphorylation, a canonical TGF- $\beta$ signaling pathway (91). These data suggest a complicated interaction between TGF- $\beta$ and TSLP and the indispensable role of TSLP in TGF- $\beta$ mediated skin fibrosis. Detailed understanding of the interplay between the primary cytokines TGF- $\beta$, IL-13 and TSLP is crucial for future SSc treatment. Recent studies have demonstrated that TSLP and IL-4 increased dramatically in SSc and correlated immediately with an elevation of Th9 responses, which were also implicated in SSc by regulating autoimmunity and autoantibody production (94).

Besides promoting the early-phase development of SSc via increased autoimmune responses, TSLP has also contributed to fibrosis in the late phases of SSc. Truchetet et al. found that administration of TSLP in the dermis induces type I collagen synthesis and decreases the production of the collagenase matrix metalloproteinase 1, markedly changing their ratio, confirming a profibrotic activity for TSLP (93). The profibrotic profile in fibroblasts was consistent with the profibrotic gene signature previously identified in the mouse model by Christmann et al. (91). Moreover, TSLP-activated fibroblasts are capable of producing TGF- $\beta$, hence inducing TSLP, leading to a selfamplifying loop (96). Given the critical role of TSLP in the early phases (endothelial injury and autoimmune inflammation) and late phases (fibrosis) of SSc, therapeutically targeted modulation of TSLP may represent a novel antifibrotic strategy in SSc patients and warrants further investigation.

\section{Chronic Spontaneous Urticaria}

Chronic spontaneous urticaria (CSU) is a chronic cutaneous disease that features recurrent itching wheals for more than six weeks without a definite eliciting factor (98). IL-25, IL-33, and TSLP affect mast cells, and notably, dermal TSLP-positive cells are markedly higher in the lesional skin of CSU than in nonlesional skin and healthy controls (99). These data suggest TSLP is implicated in the pathogenesis of CSU, and a blockade of TSLP/TSLPR signaling may provide an efficacious prospective treatment in CSU patients $(100,101)$.

\section{Behçet's Disease}

Behçet's Disease (BD) is one of the most prevalent neutrophilic dermatoses characterized by recurring damage to the mouth, eyes, genitals, and skin (102). In severe cases, multiple systems and organs could be involved (102). The expression of TSLP and IL-33 mRNA increased dramatically in the skin lesions of BD and was correlated to the disease activity, indicating that the TSLP-IL-33 axis plays a crucial part in the pathogenesis of BD, linking the environmental triggers with systemic immune disturbance $(103,104)$.

\section{Vitiligo}

Vitiligo, an acquired chronic depigmented skin disorder characterized by white macules' development, features the loss of functional epidermal melanocytes (105). The autoimmune/ autoinflammatory theory is the predominant hypothesis for vitiligo development since it is often associated with other autoimmune conditions such as thyroiditis (105, 106). TSLP polymorphisms may be essential genetic predispositions in vitiligo. An increased vitiligo susceptibility is linked with specific variants of TSLP identified by genetic studies (107, 108). In Korean patients, the TSLP-847C $>\mathrm{T}$ polymorphism was lower in vitiligo patients (107). The promoter activity of TSLP-847C decreased dramatically compared to TSLP-847T, which may enhance vitiligo susceptibility through decreased TSLP mRNA expression level, enhanced Th1 responses, and reduced Th2 activity (107). Further studies also provide robust evidence of a significant genetic association between vitiligo and TSLP (108). A case-control study was recently conducted to clarify the relationship between vitiligo and TSLP mRNA expression. A statistically lower TSLP mRNA expression in patients with generalized nonsegmental vitiligo than healthy controls was confirmed (109). Nonetheless, the expressions of TSLP at the protein levels in serum and lesional skin of patients with vitiligo have yet to be elucidated.

\section{Rosacea}

Rosacea is a chronic inflammatory disorder that occurs in the middle of the face and mainly affects facial blood vessels and the sebaceous gland (110). TSLP expression was increased in sebaceous-rich healthy donors, but the DCs are in an immature state, suggestive of a tolerogenic activity of TSLP in sebaceous gland-abundant sites of healthy skin (111). In papulopustular rosacea, a loss of immune tolerance characterized by skin DC activation and alteration of inflammatory types accounts for the skin barrier abnormality and subsequent Th1/Th17 dominating immune responses (111-113). The sebum compositions and TSLP expression markedly decreased in the skin lesion of patients with rosacea, while IFN- $\gamma$ and IL-17 elevated significantly. Dajnoki et al. hypothesized that the decreased sebum contents could potentially contribute to inhibiting tolerogenic TSLP production and changing the previous noninflammatory milieu, leading to the development of rosacea (111). However, there are few studies on the specific biological activity of TSLP in the pathogenesis of rosacea. Further investigations are needed to clarify the immunotolerant role of TSLP at the cutaneous barrier surfaces.

\section{Systemic Lupus Erythematous}

Recently, pathway-based analyses have suggested that numerous potential pathways, including TSLP signaling, could be involved in the immunopathogenesis of systemic lupus erythematosus (SLE). SLE could also present as a mucocutaneous manifestation and can be only involved in the skin, as in cutaneous lupus erythematosus $(114,115)$. However, Truchetet et al. failed to determine elevated TSLP expression in either the skin or the circulating blood in patients with SLE (93). The mechanisms of the undiscovered factors that hinder TSLP expression in SLE have not yet been identified. 


\section{Alopecia Areata}

Alopecia areata (AA) is an autoimmune disorder with a lifetime incidence of nearly $2 \%$ (116). In addition to Th1-driven immune responses, the AA transcriptome showed an increased inflammatory profile of Th2 genes, including TSLP, indicating a possibility of Th2 signaling in AA patients (117). However, the TSLP-related pathways and Th2 immune responses were inhibited in a portion of severe AA patients (118). Topical treatment with diphenylcyclopropenone upregulated the TSLP-OX40L-IL13 axis in these individuals and promoted Th2-skewing immune responses, thus repairing equilibrium between Th1/Th2 ratios (118). A deep understanding of the precise pathogenic contribution of TSLP signaling in the pathogenesis of AA may yield novel targeted therapies for AA patients.

\section{CONCLUSION AND FURTHER PERSPECTIVES}

TSLP is a critical regulator initially characterized by its ability to link innate immunity to type 2 acquired immune response at barrier surfaces. Emerging data show that TSLP can indirectly or directly affect a variety of non-immune and immune cells involved in a broad array of cutaneous immune-mediated disorders beyond just $\mathrm{AD}$, vastly widening the function of TSLP in different skin conditions.

A group retrospectively reviewed the samples of eosinophilrich dermatoses and identified that TSLP was diffusely expressed in arthropod assault, drug rash, $\mathrm{AD}, \mathrm{BP}$, and non-BP eosinophilic

\section{REFERENCES}

1. Sims JE, Williams DE, Morrissey PJ, Garka K, Foxworthe D, Price V, et al. Molecular Cloning and Biological Characterization of a Novel Murine Lymphoid Growth Factor. J Exp Med (2000) 192(5):671-80. doi: 10.1084/ jem.192.5.671

2. Leonard WJ. TSLP: Finally in the Limelight. Nat Immunol (2002) 3(7):605-7. doi: 10.1038/ni0702-605

3. Friend SL, Hosier S, Nelson A, Foxworthe D, Williams DE, Farr A. A Thymic Stromal Cell Line Supports In Vitro Development of Surface Igm + B Cells and Produces a Novel Growth Factor Affecting B and T Lineage Cells. Exp Hematol (1994) 22(3):321-8.

4. Levin SD, Koelling RM, Friend SL, Isaksen DE, Ziegler SF, Perlmutter RM, et al. Thymic Stromal Lymphopoietin: A Cytokine That Promotes the Development of Igm + B Cells In Vitro and Signals Via a Novel Mechanism. J Immunol (1999) 162(2):677-83.

5. Harada M, Hirota T, Jodo AI, Doi S, Kameda M, Fujita K, et al. Functional Analysis of the Thymic Stromal Lymphopoietin Variants in Human Bronchial Epithelial Cells. Am J Respir Cell Mol Biol (2009) 40(3):368-74. doi: 10.1165/rcmb.2008-0041OC

6. Park LS, Martin U, Garka K, Gliniak B, Di Santo JP, Muller W, et al. Cloning of the Murine Thymic Stromal Lymphopoietin (TSLP) Receptor: Formation of a Functional Heteromeric Complex Requires Interleukin 7 Receptor. J Exp Med (2000) 192(5):659-70. doi: 10.1084/jem.192.5.659

7. Pandey A, Ozaki K, Baumann H, Levin SD, Puel A, Farr AG, et al. Cloning of a Receptor Subunit Required for Signaling by Thymic Stromal Lymphopoietin. Nat Immunol (2000) 1(1):59-64. doi: 10.1038/76923

8. Reche PA, Soumelis V, Gorman DM, Clifford T, Liu M, Travis M, et al. Human Thymic Stromal Lymphopoietin Preferentially Stimulates Myeloid Cells. J Immunol (2001) 167(1):336-43. doi: 10.4049/jimmunol.167.1.336 spongiosis (84). Based on these results and the findings from the literature, TSLP is closely involved in numerous skin conditions beyond just allergy and autoimmunity. TSLP expression is upregulated in patients with cutaneous T cell lymphoma (119). Tumor cells with TSLPR produce IL-13 and IL-4 in the presence of TSLP (119). Moreover, keratinocyte-specific deletion of the Notch pathway in mouse models of skin cancer showed a tumorsuppressive potential for TSLP $(120,121)$. Additionally, TSLP has also been implicated in keloid pathogenesis (122). These data add to the complicacy of TSLP immunomodulatory activities relying on the immune milieu. Understanding the pleiotropic properties of TSLP in various immune cascades will be essential in future research and development of effective TSLP-targeted therapies for these conditions.

\section{AUTHOR CONTRIBUTIONS}

The manuscript was written by S-HW with significant contributions from Y-GZ. All authors contributed to the article and approved the submitted version.

\section{FUNDING}

This study was supported by the National Natural Science Foundation of China (grant number 81972944) and the Beijing Natural Science Foundation (grant number 7192166).

9. Quentmeier H, Drexler HG, Fleckenstein D, Zaborski M, Armstrong A, Sims JE, et al. Cloning of Human Thymic Stromal Lymphopoietin (TSLP) and Signaling Mechanisms Leading to Proliferation. Leukemia (2001) 15 (8):1286-92. doi: 10.1038/sj.leu.2402175

10. Ziegler SF, Roan F, Bell BD, Stoklasek TA, Kitajima M, Han H. The Biology of Thymic Stromal Lymphopoietin (TSLP). Adv Pharmacol (2013) 66:12955. doi: 10.1016/b978-0-12-404717-4.00004-4

11. Corren J, Ziegler SF. TSLP: From Allergy to Cancer. Nat Immunol (2019) 20 (12):1603-9. doi: 10.1038/s41590-019-0524-9

12. Soumelis V, Reche PA, Kanzler H, Yuan W, Edward G, Homey B, et al. Human Epithelial Cells Trigger Dendritic Cell Mediated Allergic Inflammation by Producing TSLP. Nat Immunol (2002) 3(7):673-80. doi: $10.1038 /$ ni805

13. Kashyap M, Rochman Y, Spolski R, Samsel L, Leonard WJ. Thymic Stromal Lymphopoietin Is Produced by Dendritic Cells. J Immunol (2011) 187 (3):1207-11. doi: 10.4049/jimmunol.1100355

14. Allakhverdi Z, Comeau MR, Jessup HK, Yoon BR, Brewer A, Chartier S, et al. Thymic Stromal Lymphopoietin Is Released by Human Epithelial Cells in Response to Microbes, Trauma, or Inflammation and Potently Activates Mast Cells. J Exp Med (2007) 204(2):253-8. doi: 10.1084/jem.20062211

15. Rochman I, Watanabe N, Arima K, Liu YJ, Leonard WJ. Cutting Edge: Direct Action of Thymic Stromal Lymphopoietin on Activated Human CD4+ T Cells. J Immunol (2007) 178(11):6720-4. doi: 10.4049/jimmunol.178.11.6720

16. Siracusa MC, Saenz SA, Hill DA, Kim BS, Headley MB, Doering TA, et al. TSLP Promotes Interleukin-3-Independent Basophil Haematopoiesis and Type 2 Inflammation. Nature (2011) 477(7363):229-33. doi: 10.1038/nature10329

17. Arai T, Sakurai D, Iinuma T, Nakagawa T, Yonekura S, Okamoto Y. Basophils From Allergic Rhinitis Patients Show Allergen-Specific Upregulation of Thymic Stromal Lymphopoietin Receptor. Ann Allergy Asthma Immunol (2018) 120(2):155-63. doi: 10.1016/j.anai.2017.12.005 
18. He B, Xu W, Santini PA, Polydorides AD, Chiu A, Estrella J, et al. Intestinal Bacteria Trigger T Cell-Independent Immunoglobulin A(2) Class Switching by Inducing Epithelial-Cell Secretion of the Cytokine APRIL. Immunity (2007) 26(6):812-26. doi: 10.1016/j.immuni.2007.04.014

19. Watanabe N, Wang YH, Lee HK, Ito T, Wang YH, Cao W, et al. Hassall's Corpuscles Instruct Dendritic Cells to Induce CD4+CD25+ Regulatory T Cells in Human Thymus. Nature (2005) 436(7054):1181-5. doi: 10.1038/ nature 03886

20. Iliev ID, Spadoni I, Mileti E, Matteoli G, Sonzogni A, Sampietro GM, et al. Human Intestinal Epithelial Cells Promote the Differentiation of Tolerogenic Dendritic Cells. Gut (2009) 58(11):1481-9. doi: 10.1136/ gut.2008.175166

21. Hanabuchi S, Ito T, Park WR, Watanabe N, Shaw JL, Roman E, et al. Thymic Stromal Lymphopoietin-Activated Plasmacytoid Dendritic Cells Induce the Generation of FOXP3+ Regulatory T Cells in Human Thymus. J Immunol (2010) 184(6):2999-3007. doi: 10.4049/jimmunol.0804106

22. Harada M, Hirota T, Jodo AI, Hitomi Y, Sakashita M, Tsunoda T, et al. Thymic Stromal Lymphopoietin Gene Promoter Polymorphisms are Associated With Susceptibility to Bronchial Asthma. Am J Respir Cell Mol Biol (2011) 44(6):787-93. doi: 10.1165/rcmb.2009-0418OC

23. Xie Y, Takai T, Chen X, Okumura K, Ogawa H. Long TSLP Transcript Expression and Release of TSLP Induced by TLR Ligands and Cytokines in Human Keratinocytes. J Dermatol Sci (2012) 66(3):233-7. doi: 10.1016/ j.jdermsci.2012.03.007

24. Datta A, Alexander R, Sulikowski MG, Nicholson AG, Maher TM, Scotton CJ, et al. Evidence for a Functional Thymic Stromal Lymphopoietin Signaling Axis in Fibrotic Lung Disease. J Immunol (2013) 191(9):486779. doi: $10.4049 /$ jimmunol. 1300588

25. Martin Mena A, Langlois A, Speca S, Schneider L, Desreumaux P, Dubuquoy L, et al. The Expression of the Short Isoform of Thymic Stromal Lymphopoietin in the Colon is Regulated by the Nuclear Receptor Peroxisome Proliferator Activated Receptor-Gamma and Is Impaired During Ulcerative Colitis. Front Immunol (2017) 8:1052. doi: 10.3389/ fimmu.2017.01052

26. Bjerkan L, Schreurs O, Engen SA, Jahnsen FL, Baekkevold ES, Blix IJ, et al. The Short Form of TSLP is Constitutively Translated in Human Keratinocytes and Has Characteristics of an Antimicrobial Peptide. Mucosal Immunol (2015) 8(1):49-56. doi: 10.1038/mi.2014.41

27. Fornasa G, Tsilingiri K, Caprioli F, Botti F, Mapelli M, Meller S, et al. Dichotomy of Short and Long Thymic Stromal Lymphopoietin Isoforms in Inflammatory Disorders of the Bowel and Skin. J Allergy Clin Immunol (2015) 136(2):413-22. doi: 10.1016/j.jaci.2015.04.011

28. Dong H, Hu Y, Liu L, Zou M, Huang C, Luo L, et al. Distinct Roles of Short and Long Thymic Stromal Lymphopoietin Isoforms in House Dust MiteInduced Asthmatic Airway Epithelial Barrier Disruption. Sci Rep (2016) 6:39559. doi: $10.1038 /$ srep39559

29. Varricchi G, Pecoraro A, Marone G, Criscuolo G, Spadaro G, Genovese A, et al. Thymic Stromal Lymphopoietin Isoforms, Inflammatory Disorders, and Cancer. Front Immunol (2018) 9:1595. doi: 10.3389/fimmu.2018.01595

30. Gandolfo S, Bulfoni M, Fabro C, Russi S, Sansonno D, Di Loreto C, et al. Thymic Stromal Lymphopoietin Expression From Benign Lymphoproliferation to Malignant B-cell Lymphoma in Primary Sjogren's Syndrome. Clin Exp Rheumatol (2019) 37 Suppl 118(3):55-64.

31. Hammad H, Lambrecht BN. Barrier Epithelial Cells and the Control of Type 2 Immunity. Immunity (2015) 43(1):29-40. doi: 10.1016/j.immuni.2015.07.007

32. Ito $\mathrm{T}$, Wang $\mathrm{YH}$, Duramad $\mathrm{O}$, Hori $\mathrm{T}$, Delespesse GJ, Watanabe $\mathrm{N}$, et al. TSLP-Activated Dendritic Cells Induce an Inflammatory T Helper Type 2 Cell Response Through OX40 Ligand. J Exp Med (2005) 202(9):1213-23. doi: $10.1084 /$ jem. 20051135

33. Ochiai S, Jagot F, Kyle RL, Hyde E, White RF, Prout M, et al. Thymic Stromal Lymphopoietin Drives the Development of IL-13(+) Th2 Cells. Proc Natl Acad Sci USA (2018) 115(5):1033-8. doi: 10.1073/pnas.1714348115

34. Omori M, Ziegler S. Induction of IL-4 Expression in CD4(+) T Cells by Thymic Stromal Lymphopoietin. J Immunol (2007) 178(3):1396-404. doi: 10.4049/jimmunol.178.3.1396

35. Kitajima M, Lee HC, Nakayama T, Ziegler SF. TSLP Enhances the Function of Helper Type 2 Cells. Eur J Immunol (2011) 41(7):1862-71. doi: 10.1002/ eji.201041195
36. Kim BS, Siracusa MC, Saenz SA, Noti M, Monticelli LA, Sonnenberg GF, et al. TSLP Elicits IL-33-Independent Innate Lymphoid Cell Responses to Promote Skin Inflammation. Sci Transl Med (2013) 5(170):170ra16. doi: $10.1126 /$ scitranslmed.3005374

37. Han H, Headley MB, Xu W, Comeau MR, Zhou B, Ziegler SF. Thymic Stromal Lymphopoietin Amplifies the Differentiation of Alternatively Activated Macrophages. J Immunol (2013) 190(3):904-12. doi: 10.4049/ jimmunol.1201808

38. Salter BM, Oliveria JP, Nusca G, Smith SG, Watson RM, Comeau M, et al. Thymic Stromal Lymphopoietin Activation of Basophils in Patients With Allergic Asthma Is IL-3 Dependent. J Allergy Clin Immunol (2015) 136 (6):1636-44. doi: 10.1016/j.jaci.2015.03.039

39. Salabert-Le Guen N, Hemont C, Delbove A, Poli C, Braudeau C, Fantou A, et al. Thymic Stromal Lymphopoietin Does Not Activate Human Basophils. J Allergy Clin Immunol (2018) 141(4):1476-9.e6. doi: 10.1016/j.jaci.2017.11.012

40. Nakashima C, Otsuka A, Kabashima K. Recent Advancement in the Mechanism of Basophil Activation. J Dermatol Sci (2018) 91(1):3-8. doi: 10.1016/j.jdermsci.2018.03.007

41. Leyva-Castillo JM, Hener P, Michea P, Karasuyama H, Chan S, Soumelis V, et al. Skin Thymic Stromal Lymphopoietin Initiates Th2 Responses Through an Orchestrated Immune Cascade. Nat Commun (2013) 4:2847. doi: 10.1038/ ncomms 3847

42. Hussain M, Borcard L, Walsh KP, Pena Rodriguez M, Mueller C, Kim BS, et al. Basophil-Derived IL-4 Promotes Epicutaneous Antigen Sensitization Concomitant With the Development of Food Allergy. J Allergy Clin Immunol (2018) 141(1):223-34.e5. doi: 10.1016/j.jaci.2017.02.035

43. Brauweiler AM, Goleva E, Leung DYM. Staphylococcus Aureus Lipoteichoic Acid Initiates a TSLP-Basophil-IL4 Axis in the Skin. J Invest Dermatol (2020) 140(4):915-7.e2. doi: 10.1016/j.jid.2019.09.004

44. Noti M, Kim BS, Siracusa MC, Rak GD, Kubo M, Moghaddam AE, et al. Exposure to Food Allergens Through Inflamed Skin Promotes Intestinal Food Allergy Through the Thymic Stromal Lymphopoietin-Basophil Axis. J Allergy Clin Immunol (2014) 133(5):1390-9.e1-6. doi: 10.1016/ j.jaci.2014.01.021

45. Muto T, Fukuoka A, Kabashima K, Ziegler SF, Nakanishi K, Matsushita K, et al. The Role of Basophils and Proallergic Cytokines, TSLP and IL-33, in Cutaneously Sensitized Food Allergy. Int Immunol (2014) 26(10):539-49. doi: $10.1093 /$ intimm/dxu058

46. Han H, Roan F, Ziegler SF. The Atopic March: Current Insights Into Skin Barrier Dysfunction and Epithelial Cell-Derived Cytokines. Immunol Rev (2017) 278(1):116-30. doi: 10.1111/imr.12546

47. Boita M, Heffler E, Omede P, Bellocchia M, Bussolino C, Solidoro P, et al. Basophil Membrane Expression of Epithelial Cytokine Receptors in Patients With Severe Asthma. Int Arch Allergy Immunol (2018) 175(3):171-6. doi: $10.1159 / 000486314$

48. Kagoya R, Kondo K, Kishimoto-Urata M, Shimizu Y, Kikuta S, Yamasoba T. A Murine Model of Eosinophilic Chronic Rhinosinusitis Using the Topical Application of a Vitamin D3 Analog. Allergy (2020) 76(5):1432-42. doi: $10.1111 /$ all.14627

49. Avena-Woods C. Overview of Atopic Dermatitis. Am J Manag Care (2017) 23(8 Suppl):S115-S23.

50. Langan SM, Irvine AD, Weidinger S. Atopic Dermatitis. Lancet (2020) 396 (10247):345-60. doi: 10.1016/S0140-6736(20)31286-1

51. Sano Y, Masuda K, Tamagawa-Mineoka R, Matsunaka H, Murakami Y, Yamashita R, et al. Thymic Stromal Lymphopoietin Expression is Increased in the Horny Layer of Patients With Atopic Dermatitis. Clin Exp Immunol (2013) 171(3):330-7. doi: 10.1111/cei.12021

52. Yoo J, Omori M, Gyarmati D, Zhou B, Aye T, Brewer A, et al. Spontaneous Atopic Dermatitis in Mice Expressing an Inducible Thymic Stromal Lymphopoietin Transgene Specifically in the Skin. J Exp Med (2005) 202 (4):541-9. doi: 10.1084/jem.20041503

53. Chang J, Mitra N, Hoffstad O, Margolis DJ. Association of Filaggrin Loss of Function and Thymic Stromal Lymphopoietin Variation With Treatment Use in Pediatric Atopic Dermatitis. JAMA Dermatol (2017) 153(3):275-81. doi: 10.1001/jamadermatol.2016.4467

54. Berna R, Mitra N, Lou C, Wan J, Hoffstad O, Wubbenhorst B, et al. TSLP and IL-7R Variants Are Associated With Persistent Atopic Dermatitis. J Invest Dermatol (2021) 141(2):446-50.e2. doi: 10.1016/j.jid.2020.05.119 
55. Koblenzer CS. Itching and the Atopic Skin. J Allergy Clin Immunol (1999) 104(3 Pt 2):S109-13. doi: 10.1016/s0091-6749(99)70052-7

56. Oyoshi MK, Larson RP, Ziegler SF, Geha RS. Mechanical Injury Polarizes Skin Dendritic Cells to Elicit a $\mathrm{T}(\mathrm{H}) 2$ Response by Inducing Cutaneous Thymic Stromal Lymphopoietin Expression. J Allergy Clin Immunol (2010) 126(5):976-84.e1-5. doi: 10.1016/j.jaci.2010.08.041

57. Oetjen LK, Mack MR, Feng J, Whelan TM, Niu H, Guo CJ, et al. Sensory Neurons Co-Opt Classical Immune Signaling Pathways to Mediate Chronic Itch. Cell (2017) 171(1):217-28.e13. doi: 10.1016/j.cell.2017.08.006

58. Cevikbas F, Wang X, Akiyama T, Kempkes C, Savinko T, Antal A, et al. A Sensory Neuron-Expressed IL-31 Receptor Mediates T Helper CellDependent Itch: Involvement of TRPV1 and TRPA1. J Allergy Clin Immunol (2014) 133(2):448-60. doi: 10.1016/j.jaci.2013.10.048

59. Arai I, Tsuji M, Takeda H, Akiyama N, Saito S. A Single Dose of interleukin31 (IL-31) Causes Continuous Itch-Associated Scratching Behaviour in Mice. Exp Dermatol (2013) 22(10):669-71. doi: 10.1111/exd.12222

60. Wilson SR, The L, Batia LM, Beattie K, Katibah GE, McClain SP, et al. The Epithelial Cell-Derived Atopic Dermatitis Cytokine TSLP Activates Neurons to Induce Itch. Cell (2013) 155(2):285-95. doi: 10.1016/j.cell. 2013.08.057

61. Mishra SK, Wheeler JJ, Pitake S, Ding H, Jiang C, Fukuyama T, et al. Periostin Activation of Integrin Receptors on Sensory Neurons Induces Allergic Itch. Cell Rep (2020) 31(1):107472. doi: 10.1016/j.celrep.2020.03.036

62. Ruzicka T, Hanifin JM, Furue M, Pulka G, Mlynarczyk I, Wollenberg A, et al. Anti-Interleukin-31 Receptor A Antibody for Atopic Dermatitis. N Engl J Med (2017) 376(9):826-35. doi: 10.1056/NEJMoa1606490

63. Beck LA, Thaci D, Hamilton JD, Graham NM, Bieber T, Rocklin R, et al. Dupilumab Treatment in Adults With Moderate-to-Severe Atopic Dermatitis. N Engl J Med (2014) 371(2):130-9. doi: 10.1056/NEJMoa1314768

64. Puar N, Chovatiya R, Paller AS. New Treatments in Atopic Dermatitis. Ann Allergy Asthma Immunol (2021) 126(1):21-31. doi: 10.1016/j.anai.2020.08.016

65. Guttman-Yassky E, Pavel AB, Zhou L, Estrada YD, Zhang N, Xu H, et al. GBR 830, an Anti-OX40, Improves Skin Gene Signatures and Clinical Scores in Patients With Atopic Dermatitis. J Allergy Clin Immunol (2019) 144 (2):482-93.e7. doi: 10.1016/j.jaci.2018.11.053

66. Simpson EL, Parnes JR, She D, Crouch S, Rees W, Mo M, et al. Tezepelumab, an Anti-Thymic Stromal Lymphopoietin Monoclonal Antibody, in the Treatment of Moderate to Severe Atopic Dermatitis: A Randomized Phase 2a Clinical Trial. J Am Acad Dermatol (2019) 80(4):1013-21. doi: 10.1016/ j.jaad.2018.11.059

67. Armstrong AW, Read C. Pathophysiology, Clinical Presentation, and Treatment of Psoriasis: A Review. JAMA (2020) 323(19):1945-60. doi: 10.1001/jama.2020.4006

68. Rendon A, Schakel K. Psoriasis Pathogenesis and Treatment. Int J Mol Sci (2019) 20(6):1475. doi: 10.3390/ijms20061475

69. Chiricozzi A, Romanelli P, Volpe E, Borsellino G, Romanelli M. Scanning the Immunopathogenesis of Psoriasis. Int J Mol Sci (2018) 19(1):179. doi: 10.3390/ijms19010179

70. Volpe E, Pattarini L, Martinez-Cingolani C, Meller S, Donnadieu MH, Bogiatzi SI, et al. Thymic Stromal Lymphopoietin Links Keratinocytes and Dendritic Cell-Derived IL-23 in Patients With Psoriasis. J Allergy Clin Immunol (2014) 134(2):373-81. doi: 10.1016/j.jaci.2014.04.022

71. Suwarsa O, Dharmadji HP, Sutedja E, Herlina L, Sori PR, Hindritiani R, et al. Skin Tissue Expression and Serum Level of Thymic Stromal Lymphopoietin in Patients With Psoriasis Vulgaris. Dermatol Rep (2019) 11(1):8006. doi: $10.4081 /$ dr.2019.8006

72. El-Ghareeb MI, Helmy A, Al Kazzaz S, Samir H. Serum TSLP Is a Potential Biomarker of Psoriasis Vulgaris Activity. Psoriasis (Auckl) (2019) 9:59-63. doi: 10.2147/PTT.S212774

73. Sato-Deguchi E, Imafuku S, Chou B, Ishii K, Hiromatsu K, Nakayama J. Topical Vitamin D(3) Analogues Induce Thymic Stromal Lymphopoietin and Cathelicidin in Psoriatic Skin Lesions. Br J Dermatol (2012) 167(1):7784. doi: 10.1111/j.1365-2133.2012.10917.x

74. Gago-Lopez N, Mellor LF, Megias D, Martin-Serrano G, Izeta A, Jimenez F, et al. Role of Bulge Epidermal Stem Cells and TSLP Signaling in Psoriasis. EMBO Mol Med (2019) 11(11):e10697. doi: 10.15252/emmm.201910697

75. Ocampo DV, Gladman D. Psoriatic Arthritis. F1000Res (2019) 8:F1000 Faculty Rev-1665. doi: 10.12688/f1000research.19144.1
76. Fromm S, Cunningham CC, Dunne MR, Veale DJ, Fearon U, Wade SM. Enhanced Angiogenic Function in Response to Fibroblasts From Psoriatic Arthritis Synovium Compared to Rheumatoid Arthritis. Arthritis Res Ther (2019) 21(1):297. doi: 10.1186/s13075-019-2088-3

77. Koch AE. Angiogenesis as a Target in Rheumatoid Arthritis. Ann Rheum Dis (2003) 62(Suppl 2):ii60-7. doi: 10.1136/ard.62.suppl_2.ii60

78. Xie F, Meng YH, Liu LB, Chang KK, Li H, Li MQ, et al. Cervical Carcinoma Cells Stimulate the Angiogenesis Through TSLP Promoting Growth and Activation of Vascular Endothelial Cells. Am J Reprod Immunol (2013) 70 (1):69-79. doi: 10.1111/aji.12104

79. Zhang B, Wei CY, Chang KK, Yu JJ, Zhou WJ, Yang HL, et al. TSLP Promotes Angiogenesis of Human Umbilical Vein Endothelial Cells by Strengthening the Crosstalk Between Cervical Cancer Cells and Eosinophils. Oncol Lett (2017) 14(6):7483-8. doi: 10.3892/ol.2017.7121

80. Kridin K, Ludwig RJ. The Growing Incidence of Bullous Pemphigoid: Overview and Potential Explanations. Front Med (Lausanne) (2018) 5:220. doi: 10.3389/fmed.2018.00220

81. Zuo Y, Evangelista F, Culton D, Guilabert A, Lin L, Li N, et al. IgG4 Autoantibodies Are Inhibitory in the Autoimmune Disease Bullous Pemphigoid. J Autoimmun (2016) 73:111-9. doi: 10.1016/j.jaut.2016.06.019

82. Amber KT, Valdebran M, Kridin K, Grando SA. The Role of Eosinophils in Bullous Pemphigoid: A Developing Model of Eosinophil Pathogenicity in Mucocutaneous Disease. Front Med (Lausanne) (2018) 5:201. doi: 10.3389/ fmed.2018.00201

83. Zhang Y, Hwang BJ, Liu Z, Li N, Lough K, Williams SE, et al. BP180 Dysfunction Triggers Spontaneous Skin Inflammation in Mice. Proc Natl Acad Sci USA (2018) 115(25):6434-9. doi: 10.1073/pnas.1721805115

84. Valdebran M, Kowalski EH, Kneiber D, Li J, Kim J, Doan L, et al. Epidermal Expression of Eotaxins and Thymic Stromal Lymphopoietin in Eosinophil Rich Dermatoses. Arch Dermatol Res (2019) 311(9):705-10. doi: 10.1007/ s00403-019-01954-5

85. Hashimoto T, Kursewicz CD, Fayne RA, Nanda S, Shah SM, Nattkemper L, et al. Pathophysiologic Mechanisms of Itch in Bullous Pemphigoid. J Am Acad Dermatol (2020) 83(1):53-62. doi: 10.1016/j.jaad.2019.07.060

86. Li SZ, Jin XX, Ge XL, Zuo YG, Jin HZ. Thymic Stromal Lymphopoietin Is Implicated in the Pathogenesis of Bullous Pemphigoid by Dendritic Cells. J Immunol Res (2020) 2020:4594630. doi: 10.1155/2020/4594630

87. Hashimoto T, Rosen JD, Sanders KM, Yosipovitch G. Possible Roles of Basophils in Chronic Itch. Exp Dermatol (2019) 28(12):1373-9. doi: 10.1111/ exd.13705

88. Denton CP, Khanna D. Systemic Sclerosis. Lancet (2017) 390(10103):168599. doi: 10.1016/S0140-6736(17)30933-9

89. Ntelis K, Bogdanos D, Dimitroulas T, Sakkas L, Daoussis D. Platelets in Systemic Sclerosis: The Missing Link Connecting Vasculopathy, Autoimmunity, and Fibrosis? Curr Rheumatol Rep (2019) 21(5):15. doi: 10.1007/s11926-019-0815-z

90. Fuschiotti P. Current Perspectives on the Immunopathogenesis of Systemic Sclerosis. Immunotargets Ther (2016) 5:21-35. doi: 10.2147/ITT.S82037

91. Christmann RB, Mathes A, Affandi AJ, Padilla C, Nazari B, Bujor AM, et al. Thymic Stromal Lymphopoietin Is Up-Regulated in the Skin of Patients With Systemic Sclerosis and Induces Profibrotic Genes and Intracellular Signaling That Overlap With Those Induced by interleukin-13 and Transforming Growth Factor Beta. Arthritis Rheum (2013) 65(5):1335-46. doi: $10.1002 /$ art. 37859

92. Usategui A, Criado G, Izquierdo E, Del Rey MJ, Carreira PE, Ortiz P, et al. A Profibrotic Role for Thymic Stromal Lymphopoietin in Systemic Sclerosis. Ann Rheum Dis (2013) 72(12):2018-23. doi: 10.1136/annrheumdis-2012-202279

93. Truchetet ME, Demoures B, Eduardo Guimaraes J, Bertrand A, Laurent P, Jolivel V, et al. Platelets Induce Thymic Stromal Lymphopoietin Production by Endothelial Cells: Contribution to Fibrosis in Human Systemic Sclerosis. Arthritis Rheumatol (2016) 68(11):2784-94. doi: 10.1002/art.39817

94. Guggino G, Lo Pizzo M, Di Liberto D, Rizzo A, Cipriani P, Ruscitti P, et al. Interleukin-9 Over-Expression and T Helper 9 Polarization in Systemic Sclerosis Patients. Clin Exp Immunol (2017) 190(2):208-16. doi: 10.1111/ cei. 13009

95. Luong VH, Utsunomiya A, Chino T, Doanh LH, Matsushita T, Obara T, et al. Inhibition of the Progression of Skin Inflammation, Fibrosis, and Vascular Injury by Blockade of the $\mathrm{CX} 3 \mathrm{Cl} / \mathrm{Cx} 3 \mathrm{CR} 1$ Pathway in 
Experimental Mouse Models of Systemic Sclerosis. Arthritis Rheumatol (2019) 71(11):1923-34. doi: 10.1002/art.41009

96. Affandi AJ, van Roon JA. Editorial: Closing in on the Role of Thymic Stromal Lymphopoietin Inhibition as a Therapeutic Entry Point for Systemic Sclerosis. Arthritis Rheumatol (2016) 68(11):2571-4. doi: 10.1002/art.39815

97. Herro R, Antunes RDS, Aguilera AR, Tamada K, Croft M. The Tumor Necrosis Factor Superfamily Molecule Light Promotes Keratinocyte Activity and Skin Fibrosis. J Invest Dermatol (2015) 135(8):2109-18. doi: 10.1038/ jid.2015.110

98. Zuberbier T, Aberer W, Asero R, Bindslev-Jensen C, Brzoza Z, Canonica GW, et al. The EAACI/GA(2) LEN/EDF/WAO Guideline for the Definition, Classification, Diagnosis, and Management of Urticaria: The 2013 Revision and Update. Allergy (2014) 69(7):868-87. doi: 10.1111/all.12313

99. Kay AB, Clark P, Maurer M, Ying S. Elevations in T-helper-2-initiating Cytokines (Interleukin-33, Interleukin-25 and Thymic Stromal Lymphopoietin) in Lesional Skin From Chronic Spontaneous ('Idiopathic') Urticaria. $\mathrm{Br} \mathrm{J}$ Dermatol (2015) 172(5):1294-302. doi: 10.1111/bjd.13621

100. Kolkhir P, Altrichter S, Munoz M, Hawro T, Maurer M. New Treatments for Chronic Urticaria. Ann Allergy Asthma Immunol (2020) 124(1):2-12. doi: 10.1016/j.anai.2019.08.014

101. Maurer M, Khan DA, Elieh Ali Komi D, Kaplan AP. Biologics for the Use in Chronic Spontaneous Urticaria: When and Which. J Allergy Clin Immunol Pract (2021) 9(3):1067-78. doi: 10.1016/j.jaip.2020.11.043

102. Scherrer MAR, Rocha VB, Garcia LC. Behcet's Disease: Review With Emphasis on Dermatological Aspects. Bras Dermatol (2017) 92(4):452-64. doi: 10.1590/abd1806-4841.20177359

103. Kacem O, Kaabachi W, Dhifallah IB, Hamzaoui A, Hamzaoui K. Elevated Expression of TSLP and IL-33 in Behcet's Disease Skin Lesions: IL-37 Alleviate Inflammatory Effect of TSLP. Clin Immunol (2018) 192:14-9. doi: 10.1016/j.clim.2018.03.016

104. Murdaca G, Greco M, Tonacci A, Negrini S, Borro M, Puppo F, et al. Il-33/Il31 Axis in Immune-Mediated and Allergic Diseases. Int J Mol Sci (2019) 20 (23):5856. doi: 10.3390/ijms20235856

105. Ezzedine K, Eleftheriadou V, Whitton M, van Geel N. Vitiligo. Lancet (2015) 386(9988):74-84. doi: 10.1016/S0140-6736(14)60763-7

106. Boniface K, Seneschal J, Picardo M, Taieb A. Vitiligo: Focus on Clinical Aspects, Immunopathogenesis, and Therapy. Clin Rev Allergy Immunol (2018) 54(1):52-67. doi: 10.1007/s12016-017-8622-7

107. Cheong KA, Chae SC, Kim YS, Kwon HB, Chung HT, Lee AY. Association of Thymic Stromal Lymphopoietin Gene $-847 \mathrm{C}>\mathrm{T}$ Polymorphism in Generalized Vitiligo. Exp Dermatol (2009) 18(12):1073-5. doi: 10.1111/ j.1600-0625.2009.00897.x

108. Birlea SA, Jin Y, Bennett DC, Herbstman DM, Wallace MR, McCormack WT, et al. Comprehensive Association Analysis of Candidate Genes for Generalized Vitiligo Supports XBP1, FOXP3, and TSLP. J Invest Dermatol (2011) 131(2):371-81. doi: 10.1038/jid.2010.337

109. Elmasry MF, Nagui NAR, Rashed LA, El Darbi R. Cutaneous Expression of Thymic Stromal Lymphopoietin (TSLP) in Vitiligo Patients: A Case-Control Study. Int J Dermatol (2019) 58(5):589-92. doi: 10.1111/ijd.14282

110. van Zuuren EJ. Rosacea. N Engl J Med (2017) 377(18):1754-64. doi: 10.1056/ NEJMcp 1506630

111. Dajnoki Z, Beke G, Kapitany A, Mocsai G, Gaspar K, Ruhl R, et al. Sebaceous Gland-Rich Skin Is Characterized by TSLP Expression and Distinct Immune
Surveillance Which Is Disturbed in Rosacea. J Invest Dermatol (2017) 137 (5):1114-25. doi: 10.1016/j.jid.2016.12.025

112. Forton FMN. The Pathogenic Role of Demodex Mites in Rosacea: A Potential Therapeutic Target Already in Erythematotelangiectatic Rosacea? Dermatol Ther (Heidelb) (2020) 10(6):1229-53. doi: 10.1007/s13555-020-00458-9

113. Buhl T, Sulk M, Nowak P, Buddenkotte J, McDonald I, Aubert J, et al. Molecular and Morphological Characterization of Inflammatory Infiltrate in Rosacea Reveals Activation of Th1/Th17 Pathways. J Invest Dermatol (2015) 135(9):2198-208. doi: 10.1038/jid.2015.141

114. Gorji AE, Roudbari Z, Alizadeh A, Sadeghi B. Investigation of Systemic Lupus Erythematosus (SLE) With Integrating Transcriptomics and Genome Wide Association Information. Gene (2019) 706:181-7. doi: 10.1016/ j.gene.2019.05.004

115. Fortuna G, Brennan MT. Systemic Lupus Erythematosus: Epidemiology, Pathophysiology, Manifestations, and Management. Dent Clin North Am (2013) 57(4):631-55. doi: 10.1016/j.cden.2013.06.003

116. Pratt CH, King LE Jr., Messenger AG, Christiano AM, Sundberg JP. Alopecia Areata. Nat Rev Dis Primers (2017) 3:17011. doi: 10.1038/nrdp.2017.11

117. Suarez-Farinas M, Ungar B, Noda S, Shroff A, Mansouri Y, Fuentes-Duculan J, et al. Alopecia Areata Profiling Shows TH1, TH2, and IL-23 Cytokine Activation Without Parallel TH17/TH22 Skewing. J Allergy Clin Immunol (2015) 136(5):1277-87. doi: 10.1016/j.jaci.2015.06.032

118. Gong Y, Luo L, Li L, He X, Lu W, Sha X, et al. Diphenylcyclopropenone Plays an Effective Therapeutic Role by Up-Regulating the TSLP/OX40L/IL-13 Pathway in Severe Alopecia Areata. Exp Dermatol (2021) 30(2):278-83. doi: 10.1111/exd.14254

119. Takahashi N, Sugaya M, Suga H, Oka T, Kawaguchi M, Miyagaki T, et al. Thymic Stromal Chemokine TSLP Acts Through Th2 Cytokine Production to Induce Cutaneous T-Cell Lymphoma. Cancer Res (2016) 76(21):6241-52. doi: 10.1158/0008-5472.CAN-16-0992

120. Di Piazza M, Nowell CS, Koch U, Durham AD, Radtke F. Loss of Cutaneous TSLP-Dependent Immune Responses Skews the Balance of Inflammation From Tumor Protective to Tumor Promoting. Cancer Cell (2012) 22(4):47993. doi: $10.1016 /$ j.ccr.2012.08.016

121. Demehri S, Turkoz A, Manivasagam S, Yockey LJ, Turkoz M, Kopan R. Elevated Epidermal Thymic Stromal Lymphopoietin Levels Establish an Antitumor Environment in the Skin. Cancer Cell (2012) 22(4):494-505. doi: 10.1016/j.ccr.2012.08.017

122. Shin JU, Kim SH, Kim H, Noh JY, Jin S, Park CO, et al. TSLP Is a Potential Initiator of Collagen Synthesis and an Activator of CXCR4/SDF-1 Axis in Keloid Pathogenesis. J Invest Dermatol (2016) 136(2):507-15. doi: 10.1016/ j.jid.2015.11.008

Conflict of Interest: The authors declare that the research was conducted in the absence of any commercial or financial relationships that could be construed as a potential conflict of interest.

Copyright $\odot 2021$ Wang and Zuo. This is an open-access article distributed under the terms of the Creative Commons Attribution License (CC BY). The use, distribution or reproduction in other forums is permitted, provided the original author(s) and the copyright owner(s) are credited and that the original publication in this journal is cited, in accordance with accepted academic practice. No use, distribution or reproduction is permitted which does not comply with these terms. 